\title{
Study on the Training Mode of Students in Higher Vocational Colleges in the "Belt and Road" Initiative
}

\author{
Zhang Hong \\ Department of School of Marxism, Changzhou Vocational Institute of Light Industry, Changzhou 213164, \\ China
}

Keywords: the "Belt and Road” Initiative; students; personnel training

\begin{abstract}
Along with our country and foreign exchange deepened, especially since "The Belt and Road” strategy, more and more foreign students come to China to study, which puts forward higher requirements for the higher education and management of colleges and universities. In the face of this situation, this paper mainly analyzes the existing problems in the training of foreign students in China at the present stage, and point out the corresponding solutions, hoping to provide effective help for the training of foreign students in higher vocational colleges.

As early as 2015, the state has promulgated relevant policies to encourage colleges and universities in China to carry out international cooperation in running schools and increase the number of overseas students studying in China. But with the advance of "The Belt and Road", the scale of overseas students expands rapidly. Under such circumstances, higher vocational colleges, which were not valued by foreign students, also face the task of receiving and training foreign students. However, compared with most of the key institutions of higher education, higher vocational colleges in our country generally lack the experience of managing and teaching foreign students, and there are many problems to be solved in the enrolment, the education and management. Only by solving these problems can we improve the quality of the teaching of foreign students in higher vocational colleges, and improve the reputation of higher vocational colleges and maintain the image of higher education in China [1].
\end{abstract}

\section{Problems in the Training of Overseas Students in Higher Vocational Colleges}

Through the investigation and study, the author found that in the present stage, the foreign students received by the higher vocational colleges in China mainly come to China through the schools of the foreign students in their country or the recommendation of intermediary. Such a way to study in China through third parties is not only lack of stability, but also a greater consumption of manpower and material resources. In addition, the scale of students who can be recruited through third parties can not be too large. In some small and medium-sized cities, the Vocational Colleges in these areas are even less attractive to Chinese students. Under normal circumstances, students coming to China are more willing to go to undergraduate colleges. Even if we need to attend higher vocational colleges, we will tend to choose cities in coastal developed areas. In addition, our government has not formulated targeted enrollment and education system for higher vocational colleges to recruit foreign students and to educate them. At this stage, most of the Vocational Colleges in China recruit foreign students in the form of self enrollment. In the process of recruitment, the necessary supervision and supervision mechanism has not been established with the increase of overseas students in China. Compared with the development level of our country's economy, technology and education, "The Belt and Road" neighboring countries in general is relatively backward. Under such circumstances, the average quality of international students in China is generally lower than that of domestic students. However, in the process of recruiting students, some higher vocational colleges have not systematically tested the professional knowledge and the Chinese level before the students come to China, blindly pursue the scale of the students in the University, and even reduce the standard of admission to increase the number of students abroad. Under such circumstances, the quality of foreign students recruited by many vocational colleges in 
China is quite different. In these schools, some foreign students have not systematically studied Chinese before coming to China, so they have to face great difficulties in both learning and daily communication after coming to China. Under such circumstances, the quality of education can not be guaranteed. In the long run, it is bound to cause the students and educational institutions to doubt the quality of the education of the foreign students in our country, which is not conducive to the sustainable development of the educational cause of the foreign students in our country[2].

For our higher vocational colleges, the training plan for foreign students is still in the initial stage of research and needs to be perfected continuously. In most of our higher vocational colleges, the number of teachers who can communicate smoothly with foreign students is simply unable to meet the increasing size of international students. In the construction of teachers, the school and the government have not invested enough energy and funds, and there is no effective teacher training and recruitment system. Generally speaking, students studying in China for academic education mainly learn Chinese in the first year. In the next two to three years, professional courses were only learned. As we all know, it is difficult for most foreigners to learn Chinese, and it is more difficult for the students to learn and communicate in Chinese in one year. However, at present, most of the overseas students in higher vocational colleges begin to study together with ordinary students in grade two. Under such circumstances, the quality of learning of foreign students is simply not guaranteed. In China's vocational colleges, at present, less than 1/10 of the institutions or majors have set up English teaching classes for foreign students. In contrast, most vocational colleges teach Chinese to foreign students. Under such circumstances, nearly half of the foreign students feel that learning is exhausting. The practice of black college students who failed to pass the Chinese test and drunk on the streets was the best example.

Foreign students come from different countries. Their cultural background, religious beliefs and customs are different. Under such circumstances, it is essential to communicate with foreign students in different countries to solve the difficulties encountered by their overseas students. In addition, foreign student management teachers must have enough professional knowledge and cultural attainments, so as to answer the puzzles encountered by foreign students in their studies. However, at this stage, most of the foreign students in higher vocational colleges do not have enough experience in dealing with the conflict between different cultures and religious beliefs, which leads to the management of foreign students can not be carried out orderly. In addition, in some vocational colleges, the daily behavior standards, scholarship system and dormitory management system for foreign students are not sound enough. When there are problems in the life and academic work of foreign students, schools can not handle them effectively. Under such circumstances, foreign students can not rest at ease and finish their studies [3].

\section{Some Measures for Students in Higher Vocational Colleges to Strengthen Personnel Training under the "Belt and Road" Initiative}

In order to serve "The Belt and Road" strategy, in recent years in China are expanding student enrollment, and strengthen cooperation in education and the surrounding countries in this process. Under such circumstances, higher vocational colleges must protect their own education and teaching quality. In the enrollment and management of foreign students, the advanced experience of many developed countries is worthy of our reference. In many countries, the quality of foreign students is strictly monitored, and many countries have put an end to it when recruiting foreign students. In addition, a lot of countries, including the United States, have taken a severe attitude towards the illegal or violation of school rules in the country where the students are in the school, and the serious people are even dismissed and repatriated. Through these experiences, we can find that for higher vocational colleges, in order to attract foreign students, they can not pursue the quantity unilaterally and ignore the quality in the course of enrollment. Only by continuously improving the quality of teaching can we attract more and more foreign talents. In addition, it is necessary to strictly examine the qualifications of the students who are enrolled in the examination, and keep out of the school at the same time. In addition, in view of the general low level of Chinese and hard work of foreign students, our government should formulate the standard of the language 
level of the foreign students, and examine the qualifications of the foreign students in Higher Vocational Colleges in our country, and thus cause the waste of educational resources.

As early as the 80s of last century, China has enacted laws and regulations for overseas students. According to the law of our country, foreign students must abide by Chinese laws and regulations. Under such a premise, higher vocational colleges must serve the students in daily life. For the reasonable requirements of foreign students, schools must be satisfied within the scope of their abilities. However, we must see that with the deepening of Sino foreign exchanges, the scale of foreign students is increasing. Under such circumstances, the old management system and regulations have been unable to guarantee effective management of overseas students in higher vocational colleges. In this case, the author suggests that the state carefully investigate the basic situation of the present foreign students in China, and on this basis make a new management method for foreign students, so as to provide effective methods and systems for the management of foreign students in higher vocational colleges. In addition, China's higher vocational colleges must abide by the regulations of the management of foreign students, and on this basis, combined with the actual conditions of their own, formulate regulations for the management of foreign students suitable for the school, so as to provide a reliable system guarantee for the management of the students. For overseas students in higher vocational colleges, academic performance has become an important criterion for their assessment after they begin to study abroad. Under such circumstances, higher vocational colleges must conduct regular academic assessment of overseas students, so as to ensure the quality of teaching. For those students with poor academic achievement, schools should give some help according to their actual conditions. For the students who are often absent from the school and violate the school rules and discipline, the school should give warning, retreat and even dissolve in the case of repeated education. In addition, foreign students come to China to study in a long way. In life, they often have various problems due to language barriers and other reasons. In view of this situation, higher vocational colleges must give enough care and reasonable care to the life of overseas students. Finally, with the increasing number of international students coming to China, more and more vocational colleges in China begin to recruit foreign students. At the same time, some schools that do not have the qualifications to recruit foreign students will also fish in the recruitment work of foreign students. In view of this, the government must strictly carry out the enrollment and education qualification examination of the foreign students, and eliminate the college students who are not qualified for foreign students' recruitment and education and the "wild chicken university" that do not have the qualifications. In the process, the relevant departments should also give their help to those students who are deceived and cheated [4].

For higher vocational colleges, the key factor determining the quality of teaching is the quality of teachers. Due to the different cultural and educational backgrounds of the countries where the foreign students live, our teachers must adapt themselves to the needs of foreign students for education. At present, many vocational colleges in China lack the ability to teach overseas students. We can solve the problem in the following aspects. First of all, China's higher vocational colleges can work with the same type of foreign universities, and actively introduce the other excellent teachers in the process of running a school and learn from their advanced experience in running a school. Secondly, higher vocational colleges can select a number of excellent teachers to go to foreign excellent colleges and universities to exchange and study, so as to improve their teaching level and improve their communication and communication ability with foreign students. Third, for a large number of Vocational Colleges in China, the first two points are limited by the size of schools and the cost they can afford. Under such circumstances, schools must have targeted training for teachers. In the process of training, schools should focus on foreign languages, pedagogy and communicative competence in the light of the particularity of foreign students' education. In addition, higher vocational colleges must also establish and improve the teaching management and evaluation mechanism of students, so as to improve the quality of teaching in schools to cultivate students with high quality, better for the "The Belt and Road" strategy [5].

In western developed countries, such as the United States, Japan and the United Kingdom, the payment of scholarships and grants has formed a complete system. It is under this complete system 
of grant grants that these countries can attract enough outstanding overseas students. In many countries, scholarships and grants are jointly carried out by schools, governments and related enterprises. And in this process, there are many non-governmental organizations to help students in their lives. By contrast, at present, most of the Vocational Colleges in China do not set up an effective scholarship system for overseas students. Faced with this situation, governments, schools, enterprises and non-governmental organizations must speed up their actions so as to establish a diversified subsidy system for scholarships and scholarships for international students. In the process, the government must formulate relevant policies to guide schools and enterprises in the construction of the grant system. Secondly, in the process of establishing the scholarship granting mechanism of foreign students, higher vocational colleges should actively contact the social forces such as enterprises and civil organizations to provide support for the education of foreign students, and thus help the foreign students to learn more and better, and then make more students who are still in the future to study abroad. Carry out it. Finally, enterprises can specifically set up special scholarships for overseas students in Higher Vocational Colleges and use foreign students with independent learning and excellence. This can not only strengthen the cooperation between enterprises and higher vocational colleges, but also attract the outstanding students who are in urgent need of the enterprises to get employment in the enterprise, thus enriching their own talents and promoting the development of the enterprises [6].

\section{Summary}

Nowadays, with the development of China's economy and the deepening of foreign exchanges, more and more vocational colleges begin to recruit overseas students from neighboring countries. In the background of "The Belt and Road", the number of students studying abroad increased can provide more powerful personnel support for the "The Belt and Road" strategy. However, what must be seen is that the current laws and regulations about the education and management of foreign students are not perfect, and most of our higher vocational colleges are also lack of related experience in the management and education of foreign students, so there are often problems in the enrolment, management and education of the foreign students. In view of these situations, this paper expounds the corresponding solution strategies, hoping to make the students management and education level of higher vocational colleges has been effectively improved, and better for the "The Belt and Road" strategy.

\section{Acknowledgements}

Fund program: Project of Changzhou Higher Vocational Education Research Institute 2017, "One Belt One Road" Strategy for Talent Cultivation of International Students in Higher Vocational Colleges” CDGZ2017030

\section{References}

[1] Yu-Wan M O, Polytechnic S. The Risk and Risk Controlling of Higher Vocational Colleges Participating “the Belt and Road” Initiative[J]. Higher Vocational Education Exploration, 2018.

[2] Cai H. On International Cooperation and Communication of Higher Vocational Institutes in the Context of the Belt and Road Initiative[J]. Journal of Wuhu Institute of Technology, 2017.

[3] Li Z. Research on the Supply Side Reform of Higher Vocational Education under the Background of “The Belt and Road” Initiative[J]. Vocational \& Technical Education, 2018.

[4]Fan C B. On the Training Mode of French Talents under the Background of "Belt and Road Initiative"[J]. Journal of Hubei Correspondence University, 2017.

[5] Ren X J. Research on Education Development and Innovation of Higher Vocational Colleges under the Background of "the Belt and Road" Initiative[J]. Journal of Tianjin Vocational Institutes, 
2018.

[6] Shao D. On the Application of Cooperative Learning Model in Oral English Teaching in Higher Vocational Colleges[J]. Journal of Qiqihar Junior Teachers College, 2017. 